\title{
Understanding Erectile Dysfunction in Hypertensive Patients: The Need for Good Patient Management
}

This article was published in the following Dove Press journal:

Vascular Health and Risk Management

\author{
Jorge Hernández-Cerda ${ }^{1,2}$ \\ Vicente Bertomeu- \\ González ${ }^{1-3}$ \\ Pilar Zuazola' \\ Alberto Cordero $\mathbb{D}^{1-3}$ \\ 'Cardiology Department, Hospital \\ Universitario de San Juan, Alicante, Spain; \\ ${ }^{2}$ Departamento de Medicina Clínica, \\ Universidad Miguel Hernández, Elche, \\ Spain; ${ }^{3}$ Centro de Investigación \\ Biomédica en Red de Enfermedades \\ Cardiovasculares (CIBERCV), Madrid, \\ Spain
}

\begin{abstract}
Erectile dysfunction (ED) is defined as a man's consistent or recurrent inability to attain and/or maintain penile erection enough for successful vaginal intercourse. ED affects a large part of the population, increasing its incidence with age and comorbidities. It is estimated by the year 2025, 322 million men will suffer from ED. Incidence of ED has been related not only to chronic diseases such as diabetes mellitus, metabolic syndrome, hyperlipidemia, psychiatric diseases or urinary tract diseases, but also to hypertension and especially to antihypertensive treatments. This review summarizes current knowledge about the management of ED in hypertensive men and its role as cardiovascular disease predictor.
\end{abstract}

Keywords: erectile dysfunction, cardiovascular diseases, hypertension, antihypertensive agents

\section{Introduction}

Erectile dysfunction (ED) is defined as a man's consistent or recurrent inability to attain and/or maintain penile erection enough for successful vaginal intercourse. ${ }^{1}$ Erectile dysfunction affects a large part of the population, increasing its incidence with age. It is estimated by the year 2025, 322 million men will suffer from this disease. $^{2}$

Incidence of ED has been related to chronic diseases such as diabetes mellitus, metabolic syndrome, hyperlipidemia, psychiatric diseases or urinary tract diseases; but also to hypertension and especially to antihypertensive treatments. ${ }^{1}$

Many theories that explain the relationship between ED and hypertension have been proposed and the treatment of ED in hypertensive patients generates controversy. Under those circumstances, it is needed an actualized review of the relationship between these two entities which gathers the last knowledge published about this issue.

\section{Epidemiology}

Several epidemiologic studies from different countries have shown that the prevalence of erectile dysfunction is very high in the population. The Massachusetts Male Ageing Study (MMAS) evidenced that ED affects 52\% of men over 40 years in United States and the European Male Ageing Study (EMAS) showed a prevalence from $6 \%$ to $64 \%$ (average 30\%), rising with age. ${ }^{3}$

Multiple risk factors such as hypertension can heighten the possibility of suffering ED. A large registry of high-risk hypertensive patients showed that the prevalence of ED was $71 \%$, although most were light to moderate grade ${ }^{4}$ and
Correspondence: Alberto Cordero Cardiology Department, Hospital Universitario de San Juan, San Juan de Alicante 03550, Alicante, Spain Email acorderofort@gmail.com 
different studies have obtained an odds ratio range from 1.30 to 2.79 , for ED in hypertensive population. ${ }^{5}$

\section{Pathophysiology}

Penile erection is a neurovascular event modulated by psychological and hormonal factors. In sexual stimulation, the nerve impulses cause the release of neurotransmitters, mainly nitric oxide (NO), from the cavernous nerve terminals and endothelial cells relaxing factors in the penis, resulting in the relaxation of the smooth muscles of the arteries and arterioles that supply to the erectile tissue causing an increase in flow blood of the penis. At the same time, relaxation of the trabecular smooth muscle increases the distensibility of capillaries, to facilitate rapid filling and capillary system expansion. Thus, the subtunical venous plexus is compressed between the trabeculae and the tunica albuginea, resulting in almost total occlusion of venous flow. These events catch the blood inside the corpora cavernosa and carry to the penis from a flaccid position to an erection with an intracavernous pressure of approximately $100 \mathrm{~mm} \mathrm{Hg}$.

Detumescence may be the result of a cessation of the release of neurotransmitters, the second messenger's interruption by phosphodiesterase, as well as a sympathetic discharge during ejaculation. Smooth muscle contraction trabecular reopens venous vessels, blood trapped is expelled, and flaccidity returns. ${ }^{6}$ Hypertension can interfere at some points of this process, causing erectile dysfunction.

\section{Embryology}

Penis circulation and vascular system have the same embryological precedence, so penis can be considered as a prolongation of the vascular system. Therefore, it is inferred that every damage that modifies the systemic circulation will alter the penis circulation. ${ }^{7}$

\section{Arterial Stiffness}

Over the years, smooth muscle of the peripheral vascular system suffers a degeneration of its smooth muscle cells, being replaced by collagen. As consequence, penis vessels lose their ability to store the blood necessary for the penile erection.

A loss of approximately $15 \%$ of muscle cells it is needed for the beginning of blood leak at penis vessels. ${ }^{8}$ This smooth cells apoptosis is clearly related to the age and genetically defined in each person, but rat studies have shown that hypertensive rats developed earlier, penis vessels changes such as medial thickening, lumen narrowing, and increase of vascular resistance, compared with normotensive rats. ${ }^{9}$

\section{Endothelial Dysfunction}

$\mathrm{NO}$ is the main neurotransmitter involved in penile erection. In hypertension, maintained high blood pressure values leads to premature aging and increased turnover of endothelial cells, resulting in a decreased ability to release NO from the endothelium. ${ }^{10}$ This had been classically one of the proposed mechanisms to explain the relationship between hypertension and ED, but in the last years, the publication of a study has questioned this theory. Hurt et $\mathrm{al}^{11}$ had suggested that NO implicated in the sustained penile erection is delivered by neuronal NO synthase and not by endothelial NO synthase as it was thought.

\section{Testosterone}

Testosterone is necessary for the correct functioning and for the preservation of the penis structure. ${ }^{12}$ Doppler studies have shown that penile arterial insufficiency is more frequent, in men with low levels of testosterone. ${ }^{13}$ In addition, testosterone deficiency and penile arterial dysfunction appear to be physiologically related through endothelial dysfunction, being appropriate testosterone levels necessary for the maintenance of intrapenile NO synthase levels. ${ }^{5}$

The relation between testosterone levels and high blood pressure has been described in different studies. According to Mulligan $\mathrm{T}^{14}$ hypertensive men have a significantly higher risk of having low testosterone levels, compared to normotensive men (relative risk: 1.84). Many hypotheses have been proposed to explain this connection but the mechanism is not clear: some genes could intervene in both regulation of blood pressure and steroidogenesis; hypertension could act as an inhibitor of steroidogenesis; ${ }^{5}$ finally, hypertension treatment with thiazides, beta-blockers or spironolactone has been related with decreased testosterone levels. ${ }^{15}$

\section{Other Pathologies Associated with Hypertension}

Hypertension is tightly related to other pathologies such as chronic renal failure or heart failure which have been related to ED.

\section{Chronic Renal Failure}

Erectile disfunction prevalence in patients with chronic kidney disease (CKD) is almost $50-70 \%$, in different degrees. ${ }^{16,17}$ The cause of this relationship seems to be 
the uremia produced in CDK, which could cause hyperprolactinemia, reducing testosterone levels and it has been related too with an elevation of NO inhibitor levels. ${ }^{18,19}$

\section{Heart Failure}

Sexual activity absence is present in $30 \%$ of heart failure (HF) patients. ${ }^{20}$ This correlation has an important psychological factor, but HF can produce ED in different ways. On the one hand, HF is a complex syndrome associated with several metabolic alterations, which include impairment of nitric oxide synthase activity and vascular relaxation. ${ }^{20}$ On the other hand, HF has been related to anabolic deficiency. Jankowska et $\mathrm{al}^{21}$ found an inverse relation between $\mathrm{HF}$ grade (New York Heart Association) and total testosterone levels. Finally, HF patients are commonly treated with thiazides or beta-blockers, and as already mentioned above, these drugs can reduce testosterone levels.

\section{Management of Erectile Dysfunction in Hypertensive Patients}

A detailed history of the patient's disease is essential for a correct diagnosis of the cause of erectile dysfunction. It must be focused on detecting possible comorbidities, toxic habits or drugs which could explain ED, especially mental health medications which have been classically associated with sexual dysfunction. Some psychosexual factors can be the cause of the disease and should be addressed in the interview: anxiety, stress, low self-esteem, relationship with sexual partner or possible symptoms of female sexual dysfunction. Furthermore, the doctor must examine possible penis abnormalities, signs of hypogonadism, as well as perform a rectal examination to rule out prostatic pathologies. In addition, it is recommended to complement the history and exploration with basic laboratory profile, including testosterone levels.

Moreover, ED severity can be measured with the International Index of Erectile Function 5 (IIEF-5) scale. This scale is a validated, self-administered questionnaire that evaluates the most relevant aspects of male sexual function, such as erectile strength, orgasm, desire, satisfaction with intercourse, and overall satisfaction. The IIEF classifies the severity of ED into five categories stratified by score: No ED, ${ }^{22-25}$ Mild, ${ }^{17-21}$ Mild to moderate, ${ }^{12-16}$ Moderate, ${ }^{8-11}$ Severe. ${ }^{5-7,22}$

\section{Hypertension Treatment}

Hypertension medical treatment has a wide range of possibilities including beta-blockers, diuretics, angiotensin receptor blockers, calcium antagonists, mineralocorticoid antagonists, alpha-blockers, renin inhibitors and angiotensin-converting enzyme inhibitors among others. ${ }^{23}$ Blood pressure control can be achieved almost equally with all medical therapies, ${ }^{24,25}$ although some strategies add some positive issues, mainly on tolerability or side effects. Doumas et al describe that ED prevalence in untreated hypertensive patients is lower than in treated hypertensive patients. ${ }^{26}$ Moreover, hypertensive patients with blood pressure controlled also have lower prevalence of ED. ${ }^{27}$ Therefore, it is necessary to know which antihypertensive drugs are recommended in these patients (Table 1).

\section{Unrecommended Drugs}

Beta-blockers have been classically related to ED. The DELTHA study, a cross-sectional, observational study conducted in 1007 hypertensive male patients treated with a betablocker agent for at least 6 months reported a prevalence of ED as high as $71 \%{ }^{4}$ That effect was higher in first-generation beta-blockers, as propranolol, or second generation, as atenolol or metoprolol, than in newest beta-blockers, which possess vasodilatory actions through of blockade of alpha adrenoceptors and release NO. MR NOED, ${ }^{28}$ a randomized doubleblind study, compared treatment with metoprolol vs nebivolol in hypertensive patients and found a deterioration of ED in patients treated with metoprolol, while patients treated with nebivolol improved ED scores.

Aldosterone antagonist, mainly spironolactone, produces frequently ED and decreased libido. These side effects are due to the androgen receptors blockage that spironolactone produces, instead, other aldosterone antagonists like eplerenone with less affinity for these receptors, have not demonstrated higher prevalence of ED, when compared with placebo. ${ }^{29}$

Thiazide diuretics association with ED has been classically described in several studies. The Trial of Antihypertensive Interventions and Management (TAIM) ${ }^{30}$ was a randomized,

Table I Antihypertensive Treatments Recommended or Not in Patients with Erectile Dysfunction

\begin{tabular}{|c|l|}
\hline Recommended & Not Recommended \\
\hline $\begin{array}{c}\text { • First- secondgeneration beta- } \\
\text { blockers }\end{array}$ & $\bullet$ Nebivolol \\
\hline $\begin{array}{c}\text { - Aldosterone antagonist (mainly } \\
\text { aldosterone) }\end{array}$ & $\begin{array}{l}\text { - Angiotensin-converting enzyme } \\
\text { inhibitors }\end{array}$ \\
\hline$\bullet$ Thiazide diuretics & $\bullet$ Angiotensin receptor blockers \\
\hline$\bullet$ Calcium channel blockers & \\
\hline
\end{tabular}


placebo-controlled study that evaluated the effect of chlorthalidone and atenolol with placebo in overweight hypertensive patients. The TAIM study showed higher erectile problems incidence in chlorthalidone treated patients $(28 \% ; 95 \% \mathrm{CI}$ $15-41 \%$ ), compared with placebo (3\% 95\% CI 0-9\%).

\section{Recommended Drugs}

Nebivolol is a third-generation beta-blocker that produces peripherical vasodilation, blocking alfa-adrenergic receptors and inducing NO release. Cordero et al carried out a cross-sectional and observational study of 1242 hypertensive male patients treated with beta-blockers for at least 6 months and found that nebivolol was independently and inversely associated with ED (odds ratio 0.22 ; 95\% CI: $0.05-0.88){ }^{27}$ The DELTHA study showed that hypertensive patients without ED were more frequently treated with nebivolol than with other beta-blockers. ${ }^{4}$ An open, prospective study of men with hypertension, treated- with first and second-generation beta-blockers, showed an improvment in erectile function when their treatment was switched to nebivolol in $68 \%$ of patients. ${ }^{31}$

Angiotensin receptor blockers (ARB) are expected to improve the penile erection due to their block of angiotensin vasoconstrictor effect. A prospective study was performed to investigate the effect of valsartan on sexual function (measured by the IIEF) in 3.500 hypertensive males. In previously untreated patients, ED prevalence was significantly reduced from $65 \%$ to $45 \%(\mathrm{p}<0.0001)$. In patients treated with other drugs, switched to valsartan, ED prevalence was reduced from $75 \%$ to $53 \%$. $^{32}$

\section{Erectile Dysfunction Treatment}

Phosphodiesterase-5-inhibitors (PDE-5 inhibitors) still remain as the first-line drugs for the treatment of erectile dysfunction in patients with normal testosterone levels. ${ }^{33}$ The effects of PDE-5 inhibitor therapy combined with antihypertensive drugs were studied by Bohm et al analyzing 35 double-blind, placebo-controlled, and randomized investigations, with a total of 8115 patients divided into two groups: placebo and sildenafil. The analysis of data obtained an equal frequency of adverse events related to antihypertensive treatment in both groups, without influence by the number of different antihypertensives administered. The occurrence of adverse effects associated with blood pressure was low, and was comparable between the individual groups. ${ }^{34}$

Due to vasodilator effect of PDE-5 inhibitors, hypertensive patients can benefit from combinate treatment with antihypertensive and PDE-5 inhibitors. Furthermore, an effective treatment with PDE-5 inhibitors could reduce CVD risk in two ways. First, as result of ED, patients reduce the sexual intercourse frequency and a low frequency of sexual activity (once a month or less) have been identified as an independent risk factor of a high CVD risk (hazard ratio 1.45; 95\% CI: 1.04-2.01), compared with 2 or more intercourse per week. ${ }^{35}$ Second, a low CVD treatment adherence is related to a higher risk of adverse events ${ }^{36}$ and PDE-5 inhibitors treatment has been associated with an improvement in antihypertensive drug adherence. ${ }^{37}$

Although PDE-5 inhibitors are generally secure in combination with antihypertensive drugs, the administration with organic nitrates or guanylate cyclase stimulators as riociguat is contraindicated due to the risk of symptomatic hypotension. This interaction is explained by the following mechanism. The enzyme PDE5 is found mainly in the blood vessels of the corpus cavernosum, but also in the systemic and cardiac vessels. When PDE5 is activated, it breaks down cGMP, reducing smooth muscle relaxation; so PDE5 inhibitors will produce a decrease in cGMP degradation, increasing their levels. On the other hand, all the different formulations of organic nitrates are considered to increase NO levels, which in turn increases cGMP levels. If a decreased degradation of cGMP is added to an increased production, the result is an elevated hypotensive response. ${ }^{38}$ In spite of the contraindication, recent studies have suggested the utility of the combination of both drugs in the treatment of resistant hypertension and pulmonary hypertension. ${ }^{39}$

Testosterone replacement therapy (TRT) is a secondline treatment for ED in patients with hypogonadism. A large meta-analysis that studied a total of 17 randomized placebo-controlled trials ${ }^{40}$ proved that TRT improved ED scores in almost $33-75 \%$ of patients with hypogonadism. The treatment with TRT in patients with increased risk of cardiovascular disease (CVD) causes controversy. Some studies suggested an increased risk of CVD in patients treated with TRT; the Testosterone in Older Men with Mobility Limitations (TOM trial), ${ }^{41}$ was a placebocontrolled randomized trial to investigate adverse events associated to TRT and included a total of 209 men (mean age, 74 years) with a total serum testosterone level of 100 to $350 \mathrm{ng} / \mathrm{dl}$. Most of these men suffered from chronic diseases such as hypertension. After 6 months of treatment, in the TRT group, 23 men suffered adverse cardiovascular events, compared with 7 men in the placebo group, suggesting a higher risk of cardiovascular events 
in patients treated with TRT and the trial was stopped. Xu et $\mathrm{al}^{42}$ conduced a meta-analysis including 27 placebocontrolled randomized trials and found an increased risk of a cardiovascular-related event (odds ratio: 1.54, 95\% Confidence Interval: 1.09-2.18) in men treated with TRT compared with men treated with placebo.

On the other hand, recent studies have shown that TRT can be a safe treatment in patients with hypogonadism and increased risk of CVD. Sharma et $\mathrm{al}^{43}$ retrospectively examined 83,010 men with documented low testosterone levels. They found a significant reduction in all-cause mortality, myocardial infarction, and stroke, in patients treated with TRT, compared with untreated patients. Cheetham et $\mathrm{al}^{44}$ conducted a retrospective review which compared 8808 hypogonadal men who received TRT and 35,527 untreated hypogonadal patients and found a lower risk of CVD in treated patients. Traish et $\mathrm{al}^{45}$ recently published an observational prospective study in 656 men with symptomatic hypogonadism, 360 of whom received TRT, and 296 not received any treatment. The incidence of death in 10 patient-years was 0.1145 in the control group (95\% CI: $0.0746-0.1756)$ and 0.0092 in the TRT group (95\% CI: 0.0023-0.0368), with an estimated reduction in mortality for the TRT group between $66 \%$ and $92 \%$. The study also suggested a progressive decrease in systolic blood pressure and diastolic blood pressure from baseline in patients treated with TRT. Corona et $\mathrm{al}^{46}$ recently published a random effect meta-analysis considering all available data from pharmaco-epidemiological studies as well as randomized placebo-controlled trials to study the association between TRT and cardiovascular risk in men. They finally analyzed 32 trials and concluded that TRT was not associated with any significant difference in the incidence of major adverse cardiovascular events with respect to placebo (odds ratio: 0.97 ; 95\% confidence interval 0.64 $1.46 ; \mathrm{p}=0,88)$.

Intracavernosal injection is a second-line therapy for ED that achieves a predictable and fast erection in less than 10 minutes. Alprostadil is the most frequently used drug and it is also available as an intraurethral pellet. ${ }^{1}$ Intracavernous injections can increase peripheral blood levels of alprostadil which can result in hypotension, so care should be taken when using it together with other hypotensive drugs.

Vacuum constrictive devices are an alternative option for ED patients. These devices are cheap and do not present many problems in their use, but the degree of satisfaction among patients is low. ${ }^{1}$ Hypertensive patients do not need any special precautions or treatment modifications.

Finally, penile prosthesis is the third line treatment for ED and it is intended for patients who have failed the previous treatment options. Hypertensive patients do not need direct modifications.

\section{Lifestyle Modifications}

Hypertension and ED share some risk factors, mainly sedentary lifestyle, diet, obesity, smoking habit and an elevated alcohol consumption. Gupta et $\mathrm{al}^{47}$ conducted a large meta-analysis, including 6 clinical trials and concluded that lifestyle modifications for cardiovascular risk factors were associated with statistically significant improvement in sexual function (IIEF): weighted mean difference of 2.66 (95\% CI: 1.86-3.47). Cigarette smoking has been demonstrated as a dose-dependent risk factor for ED. He et $\mathrm{al}^{48}$ studied the association between smoking habit and ED among 7684 men without vascular disease. The odds ratio of erectile dysfunction was 1.41 (95\% CI: $1.09,1.81)$ for cigarette smokers compared with never smokers. The Massachusetts Male Ageing Study (MMAS) identified obesity as an independent predictor of ED. ${ }^{49}$ Different studies have shown a relative risk of ED in men with a body mass index $>25$ ranging from 1.5 to $3.0 .^{50}$

Physical activity has been demonstrated to reduce ED risk. The MMAS described a $70 \%$ of ED risk reduction in men who regularly exercise, compared with those who do not exercise regularly. ${ }^{49}$ A cross-sectional analysis of data from 2126 men showed an elevated prevalence of ED in those men who do not exercise in the last 30 days, compared with those who regularly exercise: odds ratio 1.94 (95\% CI: 1.32-2.83). ${ }^{51}$ Cheng et $\mathrm{at}^{52}$ conduced a meta-analysis including 11 studies and suggested a lower risk of ED in men who usually do physical activity compared with sedentary men: odds ratio 0.53 (99\% CI: 0.31, 0.91).

Benefits of Mediterranean diet in patients with cardiovascular risk have been demonstrated. ${ }^{53}$ Mediterranean diet is characterized by a high intake of olive oil, fruit, nuts, vegetables, and cereals; a moderate intake of fish and poultry; a low intake of dairy products, red meat, processed meats, and sweets; and wine in moderation, consumed with meals. This diet should be recommended for patients with ED and hypertension. A moderation of alcohol and salt consumption should be also recommended. 


\section{Erectile Dysfunction as CVD Predictor}

Arterial size is not homogeneous throughout the entire cardiovascular system. The penile arteries measure between 1 and $2 \mathrm{~cm}$ in diameter, left anterior descending artery (LAD) measures between 3 and $4 \mathrm{~cm}$ and internal carotid measures between 5 and $7 \mathrm{~cm} .{ }^{54}$ Considering this, the same arterial plaque volume might not cause symptoms of ED if it is located in penile vessels but, in contrast, could affect myocardial perfusion and induce cardiac symptoms if it is present in a coronary artery (Figure 1).

Several studies have been recently published supporting this theory. Vlachopoulos et $\mathrm{al}^{55}$ conducted a metaanalysis with 14 prospective studies involving 92,757 participants and a mean follow-up of 6.1 years. The pooled relative risks for men with ED were 1.44 (95\% CI: 1.27-1.63) for total CVD compared with men without ED. In the same way, Dong et $\mathrm{al}^{56}$ conducted a metaanalysis including 12 prospective studies and 36,744 participants and showed that the overall combined relative risks for men with ED compared with men without ED were 1.48 (95\% CI: 1.25 to 1.74 ) for CVD. Montorsi et $\mathrm{al}^{57}$ conduced the COBRA trial to investigate the prevalence of ED in patients with coronary artery disease (CAD). They found that ED prevalence in men with chronic coronary disease was $65 \%$. In these, ED symptoms appeared before CAD detection in $93 \%$ of men, with a mean time interval of $24^{12-36}$ months.

As shown above, there is evidence that suggested the importance of ED as a predictor of developing CVD and The Princeton III Consensus recommended that sexual function should be incorporated into CVD risk assessment for all men. ${ }^{58}$
A

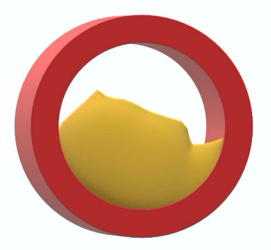

B

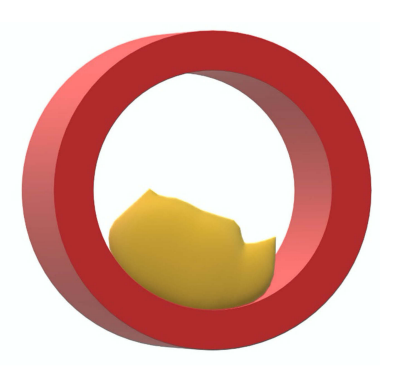

Figure I Two arterial plaques with the same size in two different arteries. (A) Penile artery: $\varnothing \mathrm{I}-2 \mathrm{~cm}$ with an obstruction $>50 \%$. (B) Coronary artery: $\varnothing 3-4 \mathrm{~cm}$ with an obstruction $<50 \%$.

\section{Future Options for Erectile Dysfunction Treatment}

Due to the high prevalence of erectile dysfunction and its impact on the quality of life of patients, the research of new therapies for treat ED never stops.

In 2016, Frey et $\mathrm{al}^{59}$ published a pilot study to investigate the effect of low-intensity extracorporeal shockwave therapy (LI-ESWT) in 16 patients with ED after bilateral nervesparing radical prostatectomy. The basis of this treatment is the hypothesis that the shockwaves increase the expression of growth factors and endothelial nitric oxide synthase, resulting in subsequent angiogenesis and regeneration of nerve fibers. The results were that after a month of treatment with LI-ESWT, patients improve IIEF score in a mean of 3.5 points (range -1 to $8 ; \mathrm{p}=0.0049$ ).

In addition, in recent years, there is a growing interest in the use of stem cells to treat ED. There are published studies based on rat models that describe an improvment in erectile function, ${ }^{60}$ but by the moment, further studies in humans are needed that provide more knowledge about this therapy.

\section{Key Take-Home Messages}

ED is a highly prevalent in patients with hypertension and has a multifactorial etiology, especially if patients also have established cardiovascular disease. We propose 4 major recommendations for patient-to-physician communication improvements:

- First: Primary prevention of cardiovascular disease, with good control of cardiovascular risk factors and avoid smoking, preserves vascular function and reduces the incidence of $\mathrm{ED}$; therefore, the first and best treatment for ED is the prevention of the main causes related to its incidence.

- Second, most patients with hypertension need medical treatments and, very often, with drug combinations. Several therapeutic families can induce or worsen and, therefore, should be avoided in patients with initial symptoms of ED. This leads to the third tip.

- Third, physicians should actively search for symptoms and signs of ED. The IIEF is feasible and reliable tool for the assessment of ED that can help physicians on decision-making but, also, patients to understand its disease.

- Fourth, once ED is clinically evident patients have an increased risk of cardiovascular events and diminished quality of life. Both issues are highly 
relevant and should encourage physicians and patients to increase risk factor control and start specific treatment, or individual assessment, of ED.

In conclusion, ED is highly prevalent in patients with hypertension. It should be actively screened, prevented and treated for physicians involved in patients with hypertension because it is a marker of higher cardiovascular risk that, also, impairs quality of life.

\section{Disclosure}

Dr Alberto Cordero reports honoraria for lectures from AstraZeneca, Bristol-Myers Squibb and AMGEN; and consulting fees from AstraZeneca, Ferrer and AMGEN. The authors report no other conflicts of interest in this work.

\section{References}

1. Shamloul R, Ghanem H. Erectile dysfunction. Lancet. 2013;381 (9861):153-165. doi:10.1016/S0140-6736(12)60520-0

2. Aytaç IA, McKinlay JB, Krane RJ. The likely worldwide increase in erectile dysfunction between 1995 and 2025 and some possible policy consequences. BJU Int. 1999;84(1):50-56. doi:10.1046/ j.1464-410x.1999.00142.x

3. Yafi FA, Jenkins L, Albersen M, et al. Erectile dysfunction. Nat Rev Dis Primers. 2016;2(1):16003. doi:10.1038/nrdp.2016.3

4. Cordero A, Bertomeu-Martínez V, Mazón P, et al. Erectile dysfunction in high-risk hypertensive patients treated with beta-blockade agents. Cardiovasc Ther. 2010;28(1):15-22. doi:10.1111/j.17555922.2009.00123.x

5. Viigimaa M, Vlachopoulos C, Doumas M. Erectile Dysfunction in Hypertension and Cardiovascular Disease. Switzerland: Springer International Publishing; 2015.

6. De F, Erección LA, Martínez-Salamanca JI, et al. Monográfico: disfunción eréctil hemodinámica: erección y detumescencia. Arch Esp Urol. 2010;63.

7. Clavijo RI, Miner MM, Rajfer J. Erectile dysfunction and essential hypertension: the same aging-related disorder? Rev Urol. 2014;16 (4):167-171.

8. Nehra A, Goldstein I, Pabby A, et al. Mechanisms of venous leakage: a prospective clinicopathological correlation of corporeal function and structure. J Urol. 1996;156(4):1320-1329. doi:10.1016/S00225347(01)65578-2

9. Jiang R, Chen JH, Jin J, Shen W, Li QM. Ultrastructural comparison of penile cavernous tissue between hypertensive and normotensive rats. Int $J$ Impot Res. 2005;17(5):417-423. doi:10.1038/sj. ijir.3901329

10. Konukoglu D, Uzun H. Endothelial dysfunction and hypertension. In: Advances in Experimental Medicine and Biology. New York LLC: Springer; 2016:511-540.

11. Hurt KJ, Sezen SF, Lagoda GF, et al. Cyclic AMP-dependent phosphorylation of neuronal nitric oxide synthase mediates penile erection. Proc Natl Acad Sci U S A. 2012;109(41):16624-16629. doi:10.1073/pnas.1213790109

12. Mirone V, Imbimbo C, Fusco F, Verze P, Creta M, Tajana G. Androgens and morphologic remodeling at penile and cardiovascular levels: a common piece in complicated puzzles? Eur Urol. 2009;56 (2):309-316. doi:10.1016/j.eururo.2008.12.037
13. Corona G, Maggi M. The role of testosterone in erectile dysfunction. Nat Rev Urol. 2010;7(1):46-56. doi:10.1038/nrurol.2009.235

14. Mulligan T, Frick MF, Zuraw QC, Stemhagen A, McWhirter C. Prevalence of hypogonadism in males aged at least 45 years: the HIM study. Int J Clin Pract. 2006;60(7):762-769. doi:10.1111/ j.1742-1241.2006.00992.x

15. Baumhäkel $M$, Schlimmer N, Kratz M, Hacket G, Jackson G, Böhm M. Cardiovascular risk, drugs and erectile function A systematic analysis. Int J Clin Pract. 2011;65(3):289-298. doi:10.1111/j.1742-1241.2010.02563.x

16. Vecchio M, Palmer SC, Tonelli M, Johnson DW, Strippoli GFM. Depression and sexual dysfunction in chronic kidney disease: a narrative review of the evidence in areas of significant unmet need. Nephrol Dial Transplant. 2012;27(9):3420-3428. doi:10.1093/ ndt/gfs 135

17. Costa MR, Ponciano VC, Costa TR, De Oliveira AM, Gomes CP, De Oliveira EC. Prevalence and factors associated with erectile dysfunction in patients with chronic kidney disease on conservative treatment. Int J Impot Res. 2017;29(6):219-224. doi:10.1038/ ijir.2017.20

18. Rosas SE, Joffe M, Franklin E, et al. Prevalence and determinants of erectile dysfunction in hemodialysis patients. Kidney Int. 2001;59 (6):2259-2266. doi:10.1046/j.1523-1755.2001.00742.x

19. Mendes Ribeiro AC, Brunini TM, Ellory JC, Mann GE. Abnormalities in ?-arginine transport and nitric oxide biosynthesis in chronic renal and heart failure. Cardiovasc Res. 2001;49 (4):697-712. doi:10.1016/S0008-6363(00)00267-4

20. Alberti L, Torlasco C, Lauretta L, et al. Erectile dysfunction in heart failure patients: a critical reappraisal. Andrology. 2013;1(2):177-191. doi:10.1111/j.2047-2927.2012.00048.x

21. Jankowska EA, Filippatos G, Ponikowska B, et al. Reduction in circulating testosterone relates to exercise capacity in men with chronic heart failure. $J$ Card Fail. 2009;15(5):442-450. doi:10.1016/j.cardfail.2008.12.011

22. Rhoden EL, Telöken C, Sogari PR, Vargas Souto CA. The use of the simplified International Index of Erectile Function (IIEF-5) as a diagnostic tool to study the prevalence of erectile dysfunction. Int J Impot Res. 2002;14(4):245-250. doi:10.1038/sj.ijir.3900859

23. Williams B, Mancia G, Spiering W, et al. 2018 ESC/ESH guidelines for the management of arterial hypertension. Eur Heart $J$. 2018;39:3021-3104.

24. Law MR, Morris JK, Wald NJ. Use of blood pressure lowering drugs in the prevention of cardiovascular disease: meta-analysis of 147 randomised trials in the context of expectations from prospective epidemiological studies. $\quad B M J . \quad 2009 ; 338$ (may19 1):1245. doi:10.1136/bmj.b1665

25. Turnbull F, Neal B, Algert $\mathrm{C}$, et al. Effects of different blood-pressure-lowering regimens on major cardiovascular events: results of prospectively-designed overviews of randomised trials. Lancet. 2003;362(9395):1527-1535.

26. Doumas M. Factors affecting the increased prevalence of erectile dysfunction in Greek hypertensive compared with normotensive subjects. J Androl. 2006;27(3):469-477. doi:10.2164/jandrol.041 91

27. Cordero A, Bertomeu-Martínez V, Mazón P, Fácila L, GonzálezJuanatey JR. Erectile dysfunction may improve by blood pressure control in patients with high-risk hypertension. Postgrad Med. 2010;122(6):51-56. doi:10.3810/pgm.2010.11.2223

28. Brixius K, Middeke M, Lichtenthal A, Jahn E, Schwinger RHG. Nitric oxide, erectile dysfunction and beta-blocker treatment $(\mathrm{Mr}$ Noed Study): benefit of nebivolol versus metoprolol in hypertensive men. Clin Exp Pharmacol Physiol. 2007;34(4):327-331. doi:10.1111/ j.1440-1681.2007.04551.x

29. Pitt B, Remme W, Zannad F, et al. Eplerenone, a selective aldosterone blocker, in patients with left ventricular dysfunction after myocardial infarction. N Engl J Med. 2003;348(14):1309-1321. 
30. Wassertheil-Smoller S, Blaufox MD, Oberman A, et al. Effect of antihypertensives on sexual function and quality of life: the TAIM study. Ann Intern Med. 1991;114(8):613-620. doi:10.7326/00034819-114-8-613

31. Doumas M, Tsakiris A, Douma S, et al. Beneficial effects of switching from beta-blockers to nebivolol on the erectile function of hypertensive patients. Asian J Androl. 2006;8(2):177-182. doi:10.1111/ j.1745-7262.2006.00076.x

32. Düsing R. Effect of the angiotensin II antagonist valsartan on sexual function in hypertensive men. Blood Press Suppl. 2003;12 (sup2):29-34. doi:10.1080/08038020310021967

33. Mobley DF, Khera M, Baum N. Recent advances in the treatment of erectile dysfunction. Postgrad Med J. 2017;93(1105):679-685. doi:10.1136/postgradmedj-2016-134073

34. Bohm M, Burkart M, Baumann G. Sildenafil is well tolerated by erectile dysfunction patients taking antihypertensive medications, including those on multidrug regimens. Curr Drug Saf. 2007;2 (1):5-8. doi:10.2174/157488607779315462

35. Hall SA, Shackelton R, Rosen RC, Araujo AB. Sexual activity, erectile dysfunction, and incident cardiovascular events. Am J Cardiol. 2010;105(2):192-197. doi:10.1016/j.amjcard.2009.08.671

36. Zullig LL, Ramos K, Bosworth HB. Improving medication adherence in coronary heart disease. Curr Cardiol Rep. 2017;19(11):113. doi:10.1007/s11886-017-0918-y

37. McLaughlin T, Harnett J, Burhani S, Scott B. Evaluation of erectile dysfunction therapy in patients previously nonadherent to long-term medications: a retrospective analysis of prescription claims. Am J Ther. 2005;12(6):605-611. doi:10.1097/01.mjt.0000181305.44330.4a

38. Kloner RA, Goggin P, Goldstein I, et al. A new perspective on the nitratephosphodiesterase type 5 inhibitor interaction. J Cardiovasc Pharmacol Ther. 2018;23(5):375-386. doi:10.1177/1074248418771896

39. Oliver JJ, Hughes VEC, Dear JW, Webb DJ. Clinical potential of combined organic nitrate and phosphodiesterase type 5 inhibitor in treatment-resistant hypertension. Hypertension. 2010;56(1):62-67. doi:10.1161/HYPERTENSIONAHA.109.147686

40. Isidori AM, Giannetta E, Gianfrilli D, et al. Effects of testosterone on sexual function in men: results of a meta-analysis. Clin Endocrinol (Oxf). 2005;63(4):381-394. doi:10.1111/j.1365-2265.2005.02350.x

41. Basaria S, Coviello AD, Travison TG, et al. Adverse events associated with testosterone administration. $N$ Engl J Med. 2010;363 (2):109-122. doi:10.1056/NEJMoa1000485

42. Xu L, Freeman G, Cowling BJ, Schooling CM. Testosterone therapy and cardiovascular events among men: a systematic review and meta-analysis of placebo-controlled randomized trials. BMC Med. 2013;11(1). doi:10.1186/1741-7015-11-108

43. Sharma R, Oni OA, Gupta K, et al. Normalization of testosterone level is associated with reduced incidence of myocardial infarction and mortality in men. Eur Heart J. 2015;36(40):2706-2715. doi:10.1093/eurheartj/ehv346

44. Cheetham TC, An JJ, Jacobsen SJ, et al. Association of testosterone replacement with cardiovascular outcomes among men with androgen deficiency. JAMA Intern Med. 2017;177(4):491-499. doi:10.1001/jamainternmed.2016.9546

45. Traish AM, Haider A, Haider KS, Doros G, Saad F. Long-term testosterone therapy improves cardiometabolic function and reduces risk of cardiovascular disease in men with hypogonadism: a real-life observational registry study setting comparing treated and untreated (control) groups. J Cardiovasc Pharmacol Ther. 2017;22(5):414-433. doi: $10.1177 / 1074248417691136$
46. Corona G, Rastrelli G, Di Pasquale G, Sforza A, Mannucci E, Maggi M. Testosterone and cardiovascular risk: meta-analysis of interventional studies. $J$ Sex Med. 2018;15(6):820-838. doi:10.1016/ j.jsxm.2018.04.641

47. Gupta BP, Murad MH, Clifton MM, Prokop L, Nehra A, Kopecky SL. The effect of lifestyle modification and cardiovascular risk factor reduction on erectile dysfunction: a systematic review and meta-analysis. Arch Intern Med. 2011;171(20):1797-1803. doi:10.1001/archinternmed.2011.440

48. He J, Reynolds K, Chen J, et al. Cigarette smoking and erectile dysfunction among Chinese men without clinical vascular disease. Am J Epidemiol. 2007;166(7):803-809. doi:10.1093/aje/kwm154

49. Derby CA, Mohr BA, Goldstein I, Feldman HA, Johannes CB, McKinlay JB. Modifiable risk factors and erectile dysfunction: can lifestyle changes modify risk? Urology. 2000;56(2):302-306. doi:10.1016/S0090-4295(00)00614-2

50. Chitaley K, Kupelian V, Subak L, Wessells H. Diabetes, obesity and erectile dysfunction: field overview and research priorities. $J$ Urol. 2009;182(6S). doi:10.1016/j.juro.2009.07.089

51. Selvin E, Burnett AL, Platz EA. Prevalence and risk factors for erectile dysfunction in the US. Am J Med. 2007;120(2):151-157. doi:10.1016/j.amjmed.2006.06.010

52. Cheng JYW, Ng EML, Ko JSN, Chen RYL. Physical activity and erectile dysfunction: meta-analysis of population-based studies. Int J Impot Res. 2007;19(3):245-252. doi:10.1038/sj.ijir.3901521

53. Estruch R, Ros E, Salas-Salvadó J, et al. Primary prevention of cardiovascular disease with a mediterranean diet. $N$ Engl $\mathrm{J} \mathrm{Med.}$ 2013;368(14):1279-1290. doi:10.1056/NEJMoa1200303

54. Montorsi P, Ravagnani PM, Galli S, et al. Association between erectile dysfunction and coronary artery disease: matching the right target with the right test in the right patient. Eur Urol. 2006;50 (4):721-731. doi:10.1016/j.eururo.2006.07.015

55. Vlachopoulos CV, Terentes-Printzios DG, Ioakeimidis NK, Aznaouridis KA, Stefanadis CI. Prediction of cardiovascular events and all-cause mortality with erectile dysfunction a systematic review and meta-analysis of cohort studies. Circ: Cardiovasc Qual Outcomes. 2013;6(1):99-109. doi:10.1161/CIRCOUTCOMES. 112.966903

56. Dong JY, Zhang YH, Qin LQ. Erectile dysfunction and risk of cardiovascular disease: meta-analysis of prospective cohort studies. $J$ Am Coll Cardiol. 2011;58(13):1378-1385. doi:10.1016/j. jacc.2011.06.024

57. Montorsi P, Ravagnani PM, Galli S, et al. Association between erectile dysfunction and coronary artery disease. Role of coronary clinical presentation and extent of coronary vessels involvement: the COBRA trial. Eur Heart J. 2006;27(22):2632-2639. doi:10.1093/ eurheartj/ehl142

58. Nehra A, Jackson G, Miner M, et al. The Princeton III consensus recommendations for the management of erectile dysfunction and cardiovascular disease. Mayo Clin Proc. 2012;87(8):766-778. doi:10.1016/j.mayocp.2012.06.015

59. Frey A, Sønksen J, Fode M. Low-intensity extracorporeal shockwave therapy in the treatment of postprostatectomy erectile dysfunction: a pilot study. Scand J Urol. 2016;50(2):123-127. doi:10.3109/ 21681805.2015.1100675

60. Chen X, Yang Q, Zheng T, et al. Neurotrophic effect of adipose tissue-derived stem cells on erectile function recovery by pigment epithelium-derived factor secretion in a rat model of cavernous nerve injury. Stem Cells Int. 2016;2016:5161248. 


\section{Publish your work in this journal}

Vascular Health and Risk Management is an international, peerreviewed journal of therapeutics and risk management, focusing on concise rapid reporting of clinical studies on the processes involved in the maintenance of vascular health; the monitoring, prevention and treatment of vascular disease and its sequelae; and the involvement of metabolic disorders, particularly diabetes. This journal is indexed on PubMed Central and MedLine. The manuscript management system is completely online and includes a very quick and fair peerreview system, which is all easy to use. Visit http://www.dovepress. com/testimonials.php to read real quotes from published authors. 